Pedro Ponce Gregorio
Arquitecto y Máster en Arquitectura

Universidad

Politécnica de Valencia

Doctorando del Departamento de Proyectos Arquitectónicos de la Escuela Técnica Superior de Arquitectura de Valencia

\title{
Un apunte sobre el palais
}

Keywords: Une maison - Un palais, Le Corbusier, Armée du Salut, Salvation Army, Palace for the People, Rue des Condelières on Paris

It would be on July of 1926, after the competition called by the Edmond de Polignac Princess's Foundation, when Le Corbusier obtained the commission to build what it would become his first palais, the Palais du Peuple on Paris. A project that, located on a neglected and irregular plot left behind by the set of shapes already built for the main building, had to serve as an extension to the important part of dormitory that l'Armee du Salut had already established as a refugee for the homeless. This is where the present "notes" follow in: on the continuous transformation that took place on the project inside the number 35 on the Rue de Sevres, with the objective of dusting off some of the key aspects of that first creative track blurred by history; going back along the line of the Palace for the People of Paris.

Darís, número 35 de la Rue de Sèvres. Sobre los tableros de la crujía lateral del desaparecido claustro del atelier, Le Corbusier y Pierre Jeanneret conciben más de trescientos proyectos de los que solo nueve pasarán a llamarse palais. ${ }^{1}$ Un hecho, que si bien podria tildarse de insignificante dada la escasa importancia que este pudiera suponer dentro de un discurso reglado como el que se pretende, deviene en fundamental si lo contextualizamos con la dimensión que el término adquiere en el prefacio a la tercera edición de Vers une architecture, pues es precisamente ahi, a través de un breve escrito titulado "Temperatura", donde el autor habla del palais como una "máquina a habitar" "destinada a completar funciones precisas al uso de los hombres 'corrientes"'. 2

Una afirmación no exenta de contundencia que Le Corbusier precisa unas cuantas lineas más arriba en el momento de presentarnos su palais, más que como un tipo arquitectónico de raigambre puramente clásica, como parte integrante de aquella novedosa arquitectura de la que todavía hoy perviven algunos de sus rasgos esenciales. En este sentido, el arquitecto añade:

$Y$ por palacio queriamos dar a entender [afirman Le Corbusier y Pierre Jeanneret] que cada órgano de la casa, por la cualidad de su disposición en el conjunto, podría entrar en relaciones emocionales tales que revelasen la grandeza y la nobleza de una intención. Y esta intención era, para nosotros, la arquitectura.

[...] ¿Es otra cosa "que estudiar la casa para el hombre corriente", "de cualquier parte", es otra cosa que recuperar las bases humanas, la escala humana, la necesidad-tipo, la función-tipo, es otra cosa que recuperar la emoción-tipo? ${ }^{3}$ (Le Corbusier 1958, XI)
Así, una vez descubierto el verdadero significado del palais corbusieriano y su intrincada relación con la maison moderna es cuando entendemos, una vez más, la globalidad con la que el maestro interpreta esa arquitectura en la que apenas existe distinción entre cada uno de sus proyectos; como si todos ellos, independiente de su escala y dimensión, o incluso, del uso al que sean destinados, fueran fruto de un único e inalterable método. De hecho, Le Corbusier dejó buena constancia de ello a propósito de la séptima conferencia pronunciada el martes 15 de octubre de 1929 en la Facultad de Ciencias Exactas de Buenos Aires, ${ }^{4}$ cuando afirmaba que después de varios meses de trabajo,

...cuando ya habiamos terminado nuestro proyecto [de la Sociedad de Naciones], comprobamos que habiamos recorrido exactamente los mismos caminos que para concebir una fábrica, un plano de ciudad, una casa, un mobiliario. $^{5}$ (Le Corbusier 1960, 166)

Tal es el convencimiento del arquitecto sobre este punto concreto de su teoría, que en 1928, como consecuencia del concurso para el proyecto del Palais de la Société des $\mathrm{Na}$ tions de Ginebra (1927), Le Corbusier publica Une maison - Un palais. À la recherche d'une unité architecturale. Un libro, que además de para demostrar la indignación producida por el rechazo de su propuesta en el concurso, le servía para poner de manifiesto la más que probada relación entre la una y el otro; como partes ecuánimes de un mismo sistema. No en vano, así lo señala el propio Le Corbusier, para quien, dado que podemos hacer de une maison, un palais; "el palais, él, será una maison" ${ }^{6}$ de hecho,

...nuestra alegría [reconocen Le Corbusier y Pierre Jeanneret] fue tratar a nuestro Palacio 
de las Naciones como habiamos tratado nuestras casas.

\section{Y concluyen:}

Esta claridad y esta pureza, ¿no son la señal de los tiempos modernos? Y ¿no es también como el signo mismo de la nueva institución que, en Ginebra, debería responder a la esperanza de las sociedades nuevas? ${ }^{7}$ (Le Corbusier 1928, 84)

Pero no es en Ginebra sino en el número 29 de la Rue des Condelières de París, a propósito del primer proyecto que el atelier construyera para l'Armée du Salut, ${ }^{8}$ donde Le Corbusier inaugura la consigna que venimos desarrollando. Esa que trataremos a continuación y que de manera irremediable sentará las bases del palais hasta los albores de nuestro tiempo.

\section{El Palais du Peuple}

Como anexo a un edificio de 1912 se eleva el Palais du Peuple (1926), así bautizado por Le Corbusier como estandarte de toda esa serie de principios teóricos que, hasta el momento, apenas habian logrado rebasar las páginas de sus escritos. Y es que, una vez el palais teórico logró encontrar las vías para constituirse es cuando observamos las no pocas similitudes que se producen entre uno y otro; como si el arte de edificar (según Le Corbusier) necesitara de la memoria escrita para así, y solo así, tornarse legible.

Ya desde el título del proyecto se demuestra en gran medida que la lectura que veni- mos efectuando del palais coincide con la idea que este pretende demostrar. De hecho, si tenemos en cuenta que el primer Armée $d u$ Salut tiene por cometido alojar a la peuple sin hogar, cabría preguntarse si existe edificio más conveniente que un palais para tal encomienda. Así, puesto que el palais es definitivamente una maison para "el uso de los hombres "corrientes" ", 9 no podemos por menos de responder afirmativamente. ¿Acaso existe alguna duda sobre la pertinencia del sobrenombre a la hora de referirnos a este sencillo bloque de pisos del decimotercer distrito de París?

En el mes de julio de 1926, tras el concurso organizado por la Fundación Princesa Edmond de Polignac, ${ }^{10}$ Le Corbusier consigue el encargo para construir su primer palais sobre una parcela irregular dejada atrás por el conjunto de cuerpos del edificio principal. Un lugar claramente secundario pues este no se identifica en modo alguno con el grupo de estancias tradicionales, que como sólidos auténticos, apenas quedan integrados por el espacio vacio que fluye libre entre ellos: un lugar corriente y fijo -en esencia, concluso-, legible por el efecto de su precisa envolvente. Una circunstancia, que lejos de ser un problema para el arquitecto, se presentaba como más bien una oportunidad, pues

...recuperando este terreno descuidado, se liberaba frente a los nuevos dormitorios $y$ frente a los antiguos dormitorios del Palais du Peuple, un jardín a pleno sol y el amplio espacio libre de los dominios de Gobelins.

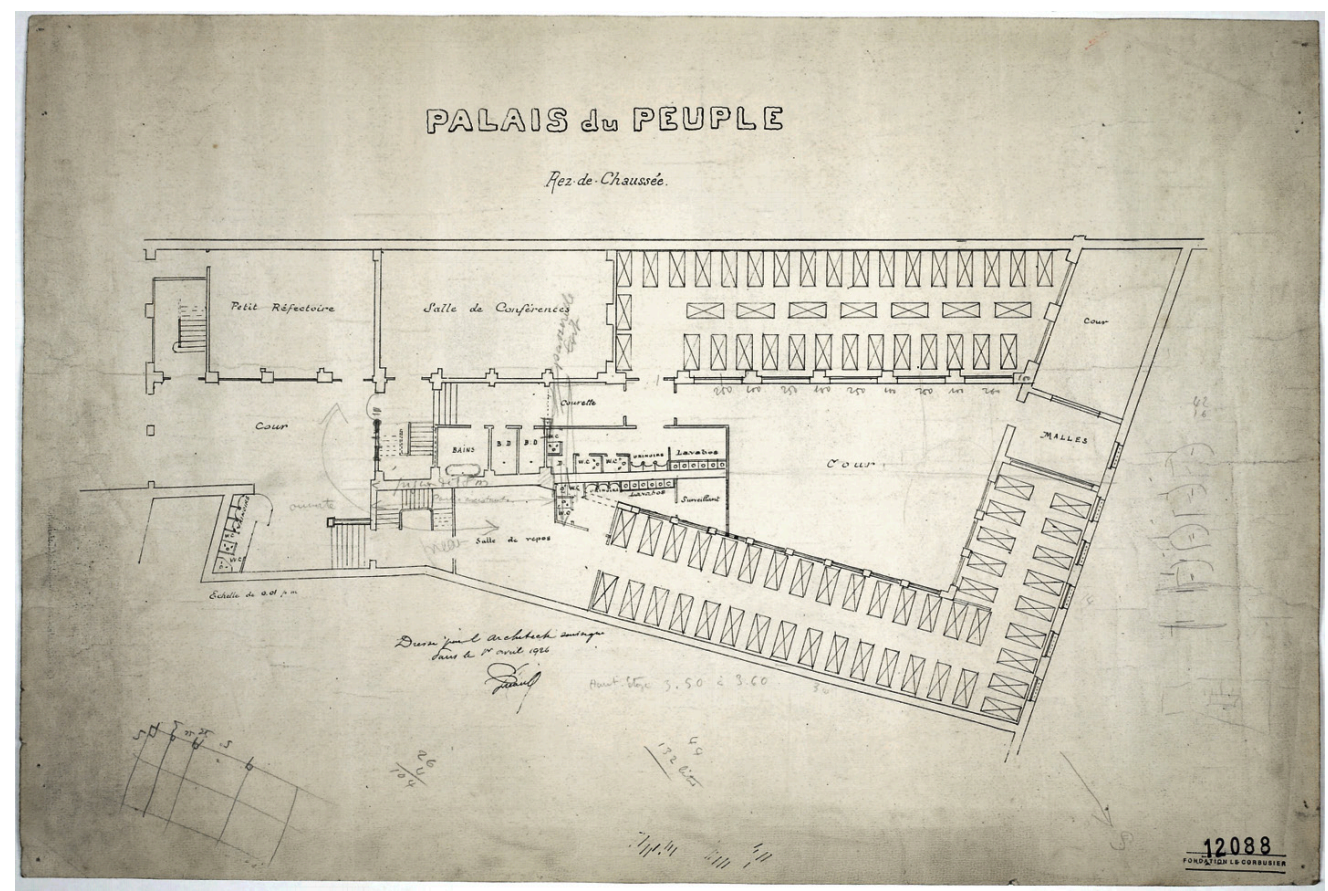

Figura 1. FLC 12088.

Planta en rez-dechaussée fechada el 1 de abril de 1926, correspondiente al proyecto diseñado por M. Préau para el Palais du PeupleCFLC-ADAGP. 


\section{En contraposición a (figura 1)}

...la solución primitivamente enviada por otros arquitectos [concretamente por M. Préau, recogida en FLC 12088], consistente en cubrir este jardin soleado por dormitorios cuya medianera estaría orientada a sur y las ventanas a norte; el edificio mismo, asi situado estaria proyectando su sombra sobre las construcciones ya existentes. ${ }^{11}$ (Boesiger 1929, 124)

Vista la parcela sobre la que Le Corbusier diseña la planta, diríamos que el proyecto para la ampliación del Palais $d u$ Peuple se plantea básicamente como un problema geométrico del que el arquitecto apenas muestra algún tipo de duda. De hecho, así lo expresa visiblemente la escasa cantidad de planos que los arquitectos del atelier desarrollaron sobre la única versión del proyecto; en contraposición, por ejemplo, al gran número de variantes y dibujos con los que se trabajarian el resto de palais. ${ }^{12}$ Como si desde el principio de los tiempos no existiese para ellos -los arquitectos-, opción más óptima a la hora de solucionar el edificio que mediante este escueto bloque de dortoirs.

Los primeros dibujos del proyecto ${ }^{13}$-FLC 12078 (planta), FLC 12079 (terraza) y FLC 12080 (axonometria)-, fechados el 2 de septiembre de 1926, parece que se esbozan sin ningún tipo de boceto previo. Resulta paradójico que presenten un aspecto similar al de cualquier plano definitivo, esto es, a tinta, perfectamente rotulados y sin apenas anotaciones o cambios (figura 2).

A partir de aquí, si comenzamos por la planta de FLC 12078, lo que más llama la atención es, sin lugar a dudas, que la escale- ra del edificio existente sea a la vez la escalera del nuevo palais. Un sencillo desvío del recorrido tradicional, reflejado en la planta con una flecha, permitía el acceso a cada uno de los niveles del nuevo bloque. Lejos queda ya aquella habitual preocupación por resolver, mediante la proliferación de escaleras particulares, el problema circulatorio que deviene del plan libre: alcanzar los contactos más convenientes entre cada una de las piezas. En cualquier caso, lo cierto es que este dispositivo puesto en marcha aquí por Le Corbusier recuerda, en mucho, los mecanismos tradicionales propios de la Antigüedad donde las piezas de escalera quedaban fuera del verdadero acontecimiento arquitectónico, y como oquedades, se sustraían del extraordinario grosor de la materia.

No deja de resultar sorprendente que dado el especial interés que el arquitecto siempre le concedía a los elementos de circulación, Le Corbusier recurriese a una de las escaleras del edificio anterior para comunicar las plantas de su palais. Así, lo que se suponía como espacio interior del bâtiment existant se incorpora, por añadidura, al límite utilizable de la parcela; tanto, como que a partir de ahí, esto es, a partir de la escalera, el nuevo edificio se despliega con la libertad propia de una pieza independiente.

Tanto es así, que a nada que recreamos el funcionamiento interno del edificio, entendemos el nuevo juego que se produce en estos peldaños, pues además de funcionar como elementos de comunicación vertical, son, dadas las circunstancias, el único paso entre la preexistencia y el nuevo palais. Una doble funcionalidad -la de circular y la de comunicar-, que lejos de resultar contradictoria, se
Figura 2. FLC 12078. "Planta tipo" del Palais du Peuple rotulada como 751 y fechada el 2 de septiembre de 1926 - OFLC-ADAGP.

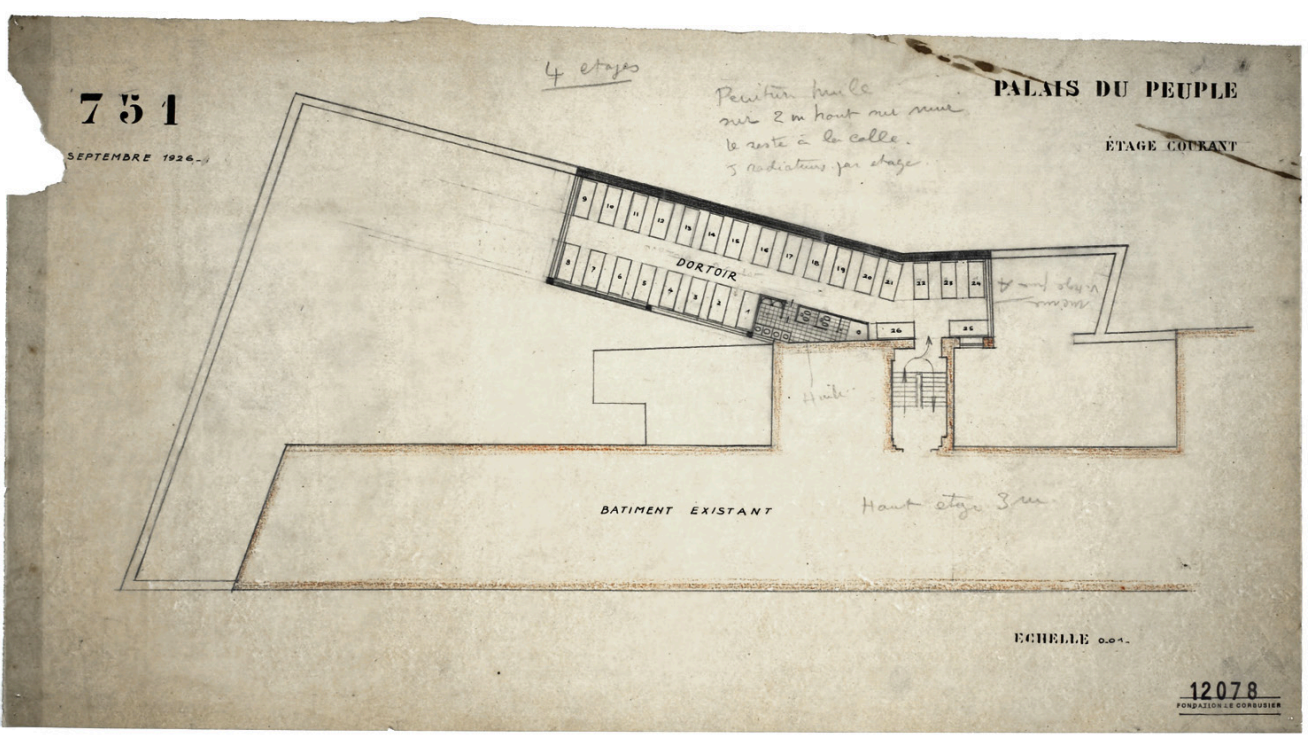


resuelve aquí bajo un único y novedoso elemento: la escalera dégagement.

No obstante, al margen de la innovación que se produce en este cuerpo de escalera, la planta FLC 12078 presenta además toda una serie de aspectos que podríamos tildar de significativos. Tal es el caso, por ejemplo, de las piezas de servicio que Le Corbusier ubica (en cada una de las cuatro plantas) ${ }^{14}$ en contacto con el bâtiment existant, y que sirven, además de para asistir las necesidades del ilustre espacio de dortoir, para dotar de una primera pauta a la distribución interior del edificio -de hecho, obsérvese cómo los extremos de la citada pieza se adecuan a las dimensiones de los camastros: tanto por la izquierda (de 2,00 m de largo) como por la derecha (de 0,80 $\mathrm{m}$ de ancho)-. Hasta el grafismo de su pavimento preludia la importancia que para el plan posee la incorporación de este pentágono irregular de servicio, que resuelve de un solo gesto la más que visible diferencia entre las dos alas del palais: una, la mayor, de 5,50 metros de anchura; y la otra, de 4 metros, apenas confinada entre el mur mitoyen y el mur existant. ${ }^{15}$

Pero al margen de todos los aspectos distributivos llevados a cabo por este primer encaje aún por depurar, llama la atención asimismo el modo con el que el arquitecto representa aquí la diferencia que existía entre los restos del pasado y los novedosos sistemas de reglas. Nos referimos, concretamente, a la desigualdad con la que se muestra el citado mur mitoyen, sombreado como una masa extraordinariamente gruesa (de $50 \mathrm{~cm}$ ), y la nueva fachada (de $25 \mathrm{~cm}$ ) de la que únicamente se distinguen sus tres soportes. De hecho, es gracias a este artificio en la repre- sentación -pues nótese cómo el dibujante diluye el cerramiento de las crujias hasta hacer irreconocible su propia materialidad-, que Le Corbusier deja constancia del contraste sobre el que habria de construir su palais, esto es, entre el muro grueso del plan paralysé y los delgados cerramientos del plan libre ${ }^{16}$ uno y otros, como distintivos de dos tradiciones que, en principio, tildariamos de irreconciliables: la maison clásica y el palais moderno, en el caso de que llegados a este punto del discurso, no fueran ya lo mismo.

La conjunción entre la circunstancia urbana, representada por el muro medianero, y el ideal constructivo oculto tras el espesor de los nuevos cerramientos, no enmascara en modo alguno la verdadera conquista que se desarrolla sobre FLC 12078. Pues gracias a que se trata de un primer esbozo del que apenas puede extraerse todavía una solución concluyente, se adivina sobre él un cierto aire de libertad a la vista de los trazos, por suerte todavía legibles, que se prolongan del cuerpo principal del palais. Es como si el edificio, a pesar de mostrarse como un elemento acabado y concluso, detentara la posibilidad de variar su dimensión -acortándose o alargándose- sin la necesidad de alterar su aspecto, o, incluso, modificar su naturaleza; bastaría un simple cambio en el número de camas para modificar la posición del testero y variar así la dimensión del palais. De ahí, quizás, la numeración de cada uno de los camastros de la planta pues son, indudablemente, los verdaderos elementos de medida: tanto de las piezas interiores de servicio, como del volumen principal del edificio.

Tal y como hemos dicho en lo anterior, la planta FLC 12078 no sería el único plano fe-

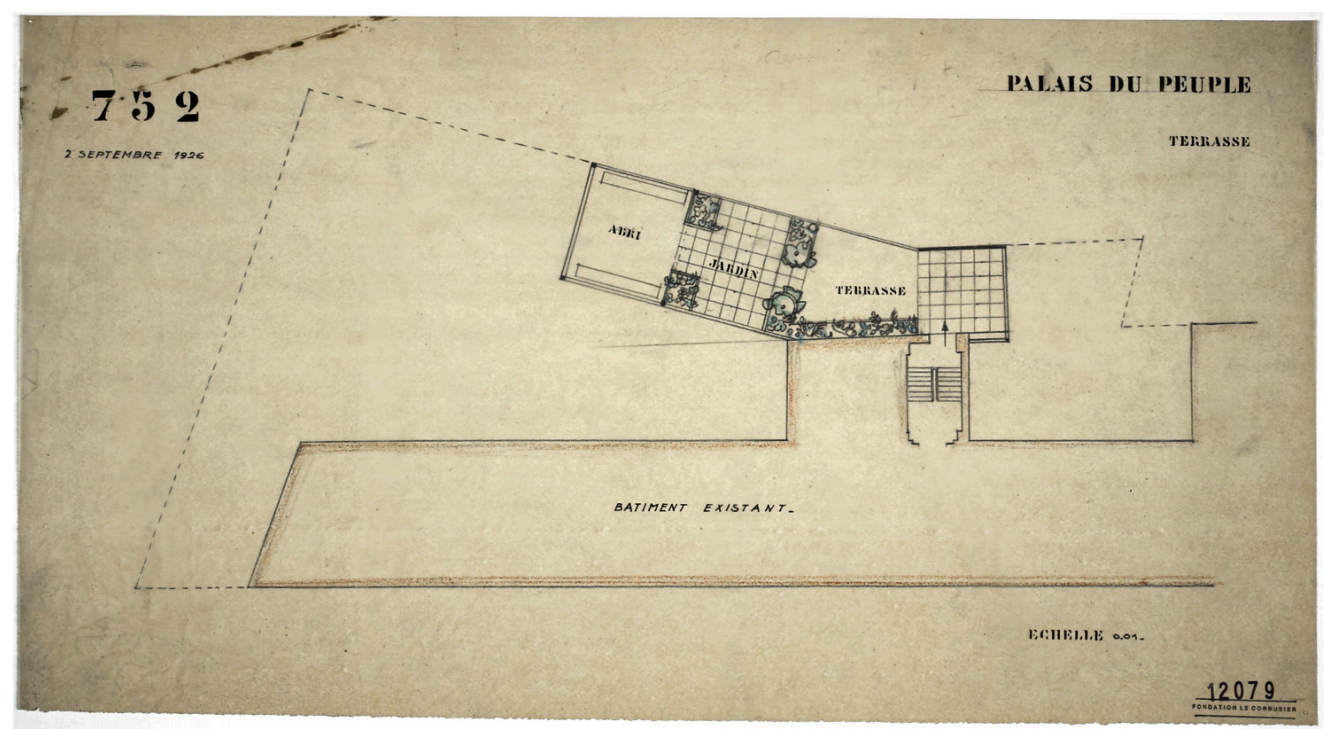

Figura 3. FLC 12079 "Terraza" del Palais du Peuple rotulada como 752 y fechada el 2 de septiembre cFLC-ADAGP. 
Figura 4. FLC 12080 Axonometría general del Palais du Peuple rotulada como $753 \mathrm{y}$ fechada el 2 de septiembre - OFLC-ADAGP.

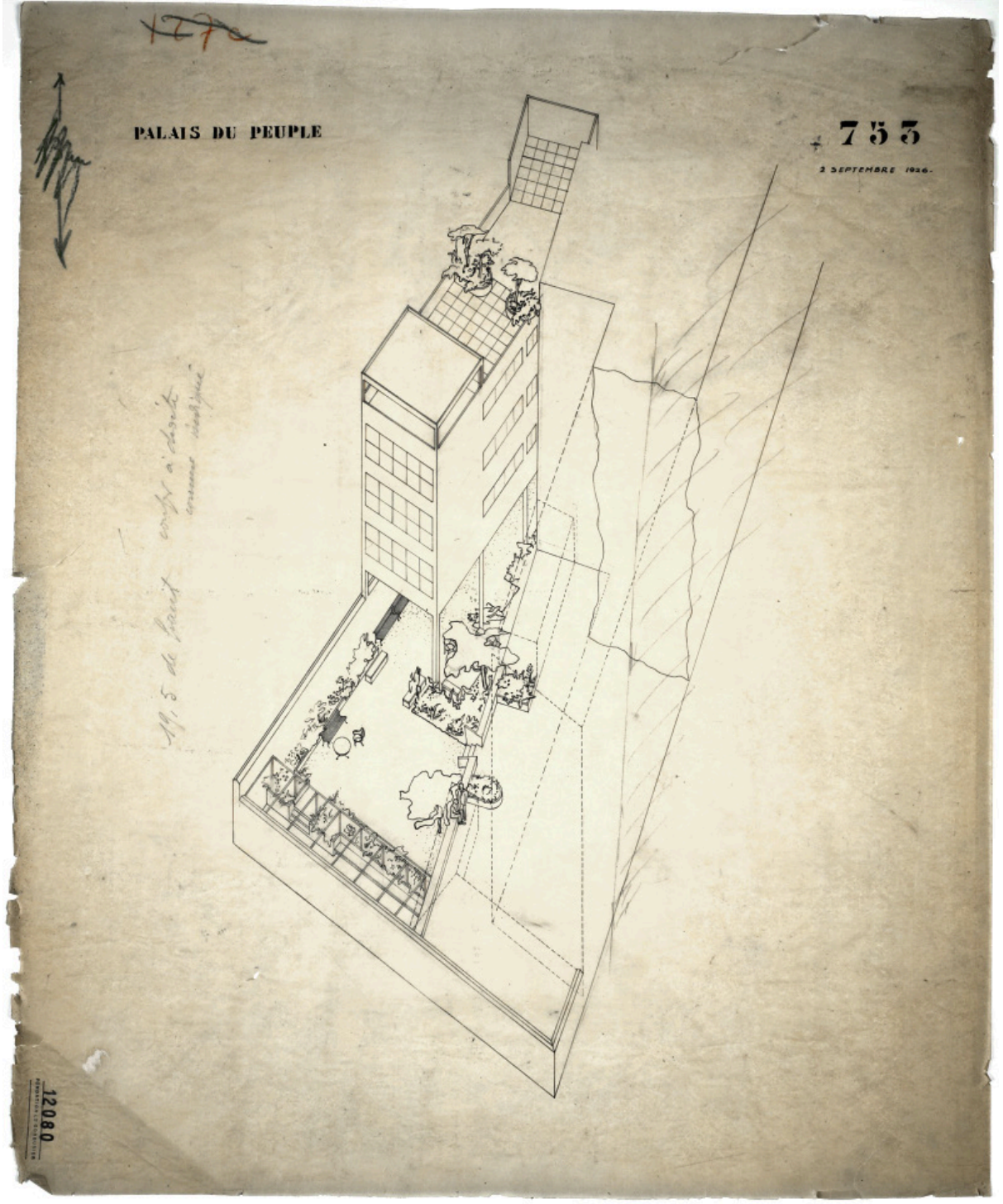

chado de este jueves día 2 de septiembre. A la par se desarrollarian también otros dos dibujos en los que se ajustan aspectos todavía pendientes sobre el plan: una planta de la terrasse-jardin (FLC 12079) que coincide en forma y dimensión con la anterior; y una axonometría general (FLC 12080) donde el arquitecto torna visible una primera modificación importante: la sustitución de la última de las plantas de dortoirs por la citada terrasse-jardin. Un ejemplo más de la verdadera libertad conquistada por Le Corbusier, para quien el proyecto de arquitectura no es otra cosa que un proceso esencialmente abierto, y como tal, sujeto a continuas modificaciones (figuras 3 y 4).

De este modo, el sencillo bloque de pisos (iguales) que intuiamos en FLC 12078, se ve aquí sustituido por un edificio que, pese a retener gran parte de sus características -tanto, como que mantiene intactas tres de las cuatro plantas de dortoirs-, incorpora el solario como colofón de esta obra asumida como incompleta. Así, una vez probada la contundencia con la que los cinco principios sacuden los distintos proyectos del arquitecto, el plan nos alerta de la más que evidente flexibilidad del encargo pues el edificio pasa de las 104 camas disponibles en el bloque de cuatro plantas, a las 78 de la variante con terraza; todo ello, dentro de los límites de un volumen aparentemente fijo que no modifica en nada -como decíamos, acortando o alargando (en función del numero de alturas)- su dimensión en planta.

Diriamos que las nuevas atribuciones funcionales del palais no enmascaran en modo alguno la que es su incorporación más significativa: la inclusión de una pieza de abri (o techo) como un ámbito más de la terrasse-jardin. Y es que, si en esencia no es otra cosa que una nueva traslación del célebre espacio entre cuatro columnas propio de las villas pompeyanas, ${ }^{17}$ cabria considerar si tras 
el aspecto de esta escueta pieza de sombra el artífice enmascara algún tipo de significado como el que el arquitecto Ivan Zaknic revela en LC Plans, cuando se refiere al palais como "el abri de l'Armée du Salut" (Fondation 2010, 1). Pues, ¿y si al margen de ser un simple elemento de sombra que corona y concluye el volumen edificado, se trata, en realidad, de la representación material del destino mismo de la obra? Mas como sabemos, si el hombre se cobija bajo las sencillas plantas del palais, podriamos entender que el edificio, en un gesto no exento de similitud, se resguarda al auxilio del abri; como si en esta pequeña pieza de techo se concentrara la quintaesencia del palais. Aquello que lo explica, define y caracteriza.

Veinte dias más tarde, esto es, el miércoles 22 de septiembre de 1926, mientras en el atelier se desarrollaban obras como las casas Cook (Boulogne-sur-Seine, 1926) y Guiette (Amberes, 1926), o proyectos urbanísticos de más envergadura como el de Berque (París, 1926), los arquitectos logran pasar a limpio en FLC 12081 la planta FLC 12078. A partir de ahí, es decir, una vez aquel primer boceto logra encajar sus partes de manera casi definitiva, se evidencia el alto grado de satisfacción que Le Corbusier mantiene hacia esta sencilla distribución en la que el encaje definitivo apenas modifica en nada el momento primero del proyecto. La planta se muestra así como el compendio de toda una serie de elementos dominantes que, a modo de invariantes compositivos, definen las distintas leyes geométricas del plan (figura 5).

Asimismo, una vez hemos reconocido la gran cantidad de similitudes que existen entre la antigua planta del arquitecto y este nuevo dibujo, no debemos pasar por alto la diferencia tan visible que existe a la hora de detallar el pavimento -que por su despiece, diriamos que es cerámico- de cada una de las áreas del palais. Pues si bien en lo anterior, esto es, en FLC 12078, la estancia principal de dortoir se representaba sin ningún tipo de trazo o trama que ayudara a reforzar la legibilidad del plano, tal y como el arquitecto hiciera en las plantas de sus viviendas, donde las áreas de estancia o reposo quedaban vacías, en FLC 12081 dibuja el pavimento con una intensidad similar a como lo hace en la pieza de servicio. Quizá por ello cabría preguntarse si este gesto, que para nada aclara la lectura de la planta, no es en realidad fruto de ese antiguo mecanismo corbusieriano gracias al cual las áreas de circulación, fuese cual fuese su importancia habrian de quedar resaltadas en los dibujos a la manera de los más estrictos espacios de servidumbre.

Entonces, ¿sería lícito considerar que Le Corbusier entiende este espacio más que como una estancia fija e inmutable, como un lugar de circulación sujeto a continuos tránsitos y modificaciones? Si nos atenemos a la declaración que el mismo arquitecto realizara en su libro Précisions según la cual "la arquitectura es la circulación", ${ }^{18}$ no podremos por menos de responder afirmativamente. Sobre todo, si recordamos que es a partir de esta nueva arquitectura por la que el hombre se desplaza que Le Corbusier introduce el tiempo al espacio; como si el movimiento, otrora relegado a las áreas secundarias del plan, fuera el verdadero molde del palais. Una importante subversión del dispositivo tradi-
Figura 5. FLC 12081. "Planta tipo" del Palais du Peuple rotulada como 764 y fechada el 22 de septiembre CFLC-ADAGP.

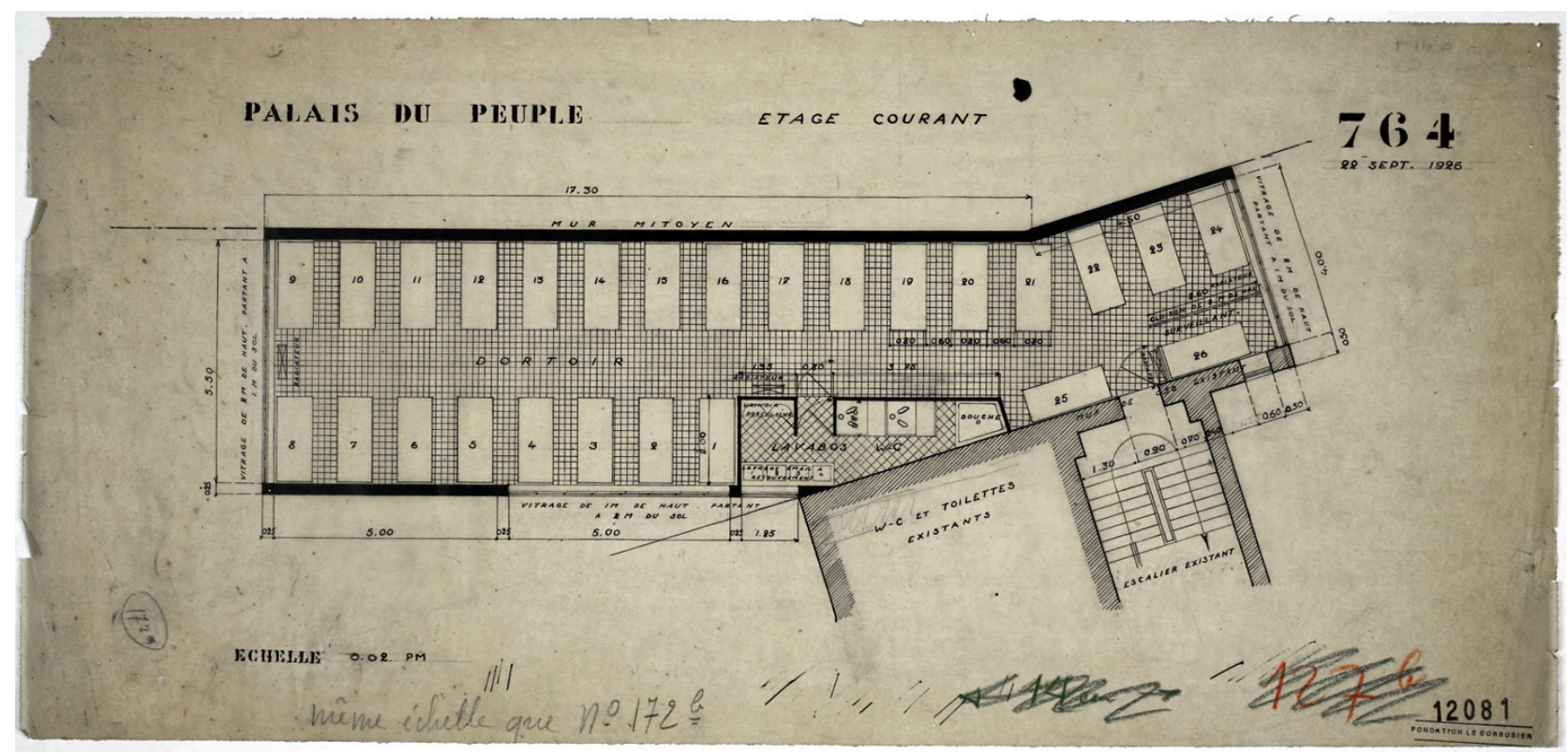


cional con la que el arquitecto representa la reversibilidad del espacio principal de dortoir; ya no desde un punto de vista estrictamente circulatorio, sino desde una visión más doméstica donde las piezas de mobiliario, aun recogiéndose en el dibujo bajo un riguroso orden, detentan la posibilidad de combinarse libremente. Incluso, en un área tan restringida como podría ser el espacio de la cama número 26 reservada al vigilante, o surveillant, la trama del pavimento nos avisa de la continuidad del espacio; tanto, como que el cerramiento que delimita este pequeño rincón de la planta no presenta la contundencia que por ejemplo sí tiene el de la sala de baños. Pues más que un tabique estable que pudiera coartar la libertad en los movimientos, es posible que Le Corbusier pretendiese para este punto concreto del plan un cerramiento más ligero: quizá, un simple cortinaje descolgado del techo.

A dia siguiente, ya jueves 23 de septiembre, los arquitectos del atelier fechan el FLC 12082, o lo que es lo mismo, un primer encaje (casi definitivo) de la planta baja del palais. En él, a pesar de que todavía se dejan pendientes ciertos aspectos como el terrain disponible en el que, como veremos en lo siguiente, Le Corbusier incorpora nuevos espacios anexos, se aporta una visión detallada de la huella que el nuevo edificio imprime sobre los dominios de los Gobelins. En este sentido, nótese el importante esfuerzo descriptivo que los arquitectos realizan a la hora de detallar cada uno de los elementos del plan: desde las superficies ajardinadas que, como un recorte, se deslizan sobre la linea de pilotis, a las innumerables piezas de asiento que se distri-
Es tal el compromiso que se adquiere a la hora de definir las áreas exteriores del palais, que Le Corbusier decide obviar sobre el dibujo aspectos otrora fundamentales como la pieza de escalera que sirve de esclusa entre el edificio existente y la nueva ampliación. Sin duda, un elemento notable del que el arquitecto decide prescindir habida cuenta de la gran cantidad de elementos que sobre la planta se manifiestan; como si ahora lo realmente importante no fuera el funcionamiento práctico del edificio sino su puesta en representación, o, dicho de otro modo, como si la apariencia de la obra, en ocasiones distorsionada por la multitud de elementos que la definen, estuviera supeditada a su propio orden interno.

Pero nada acapara tanta atención en el dibujo como el modo con el que se representa aquí la malla estructural del palais. Pues si sobre las plantas FLC 12078 y 12081 parecía clara la intención del arquitecto de construir un muro medianero de gran espesor que pudiera compensar la delgadez del resto de cerramientos, en FLC 12082 los 21,8 m de paredón se reducen a cinco pilares cuadrados de $25 \mathrm{~cm}$ separados una distancia de $5 \mathrm{~m}$. Así, el muro que intuíamos como enteramente portante en las plantas tipo del palais -pues de hecho, asi lo representaba el arquitecto-, queda determinado, a la vista de esta planta baja, como una suerte de macizo inerte en cuyo interior se subsume la verdadera estructura portante (de pilares y vigas convencionales). No representa, por tanto, una solidez real sino aparente; como si la estructura se hallara dentro de un área maciza mucho más extensa en la que, en realidad, se integra y oculta. fechada el 23 de GP. buyen sobre ellas (figura 6). 
Llegados a este punto, es decir, una vez liberada la verdadera estructura de la materia inactiva que rellena el muro, parece conveniente preguntarnos por los motivos que llevaron al arquitecto a desvelar los entresijos del palais. Y es que, si bien por un lado parece clara la intención de Le Corbusier por mostrarnos, en un punto concreto de esta planta baja, la verdadera naturaleza sobre la que se construye el muro medianero, por el otro, no resulta tan evidente el modo con el que el arquitecto lo lleva a cabo, pues el edificio, sutilmente encajado entre los estrictos limites de la parcela, abre huecos -los que resultan entre cada uno de los pilares- hacia la otra cara de la medianera. Un hecho llamativo que pone de manifiesto, una vez más, el pacto o alianza que existe entre las libertades creativas del arquitecto, capaces de redefinir los limites del planeamiento, y las rigideces propias de la ciudad; unas y otras, entendidas como elementos equivalentes dentro de la paleta de habilidades desplegada aquí por el maestro.

Pero la libertad realmente conquistada por Le Corbusier, que le distancia de otros tantos arquitectos, es la que afecta a su propio quehacer, es decir, al desarrollo de una actividad creativa que se inicia con el encaje de las grandes formas sobre el plan y continúa, de manera constante, con el afinamiento de los pequeños detalles. En este sentido, parece conveniente reparar, por ejemplo, en la escueta distinción que el arquitecto realiza entre los cinco pilares que se descubren del muro (de sección cuadrada) y los tres pilotis recayentes al jardin (de sección circular), ya no para remarcar la más que evidente dife- rencia geométrica que existe entre ambos, sino como un pretexto para consagrar, una vez más, el principio de los pilotis. Y es que al margen de ser "la consecuencia del cálculo y el resultado de la tendencia moderna a la economía", ${ }^{19}$ el piloti se nos muestra aquí como el resultado de un proceso de optimización iniciado desde el muro -donde permanece cuadrado-, para así, una vez desprendido de lo sobrante, alcanzar su más alto rango sobre el plan como un elemento aislado y continuo, capaz de recorrer la totalidad del espacio.

Así lo comprobamos en FLC 12083, donde el arquitecto dibuja por vez primera las dos únicas secciones generales que del palais podrian realizarse: una longitudinal (quebrada), con vistas hacia el edificio existente; y otra transversal, que secciona el muro medianero y muestra el testero interior del bloque. Ya no solo con el único fin de aportar una nueva visualidad al conjunto de elementos de la planta, sino como un medio en sí mismo sobre el que se realizan importantes revelaciones. Quizá por ello no nos debe sorprender que estas coupes ${ }^{20}$ del edificio, pese a constituirse como elementos inéditos dentro del proceso que venimos desarrollando, presenten un nivel de acabamiento solo comparable al de las vistas en planta. Sin duda, un hecho significativo que nos obliga a pensar que Le Corbusier no dibuja en planta hasta que no ha concebido en alzado y la sección, pues ¿cómo sino explicar la precisión y minuciosidad con la que el arquitecto representa los dibujos de FLC 12083 (figura 7)?

Sea o no así el modelo, lo cierto es que sobre estas primeras secciones del palais se observan aspectos que tan solo el arquitec-

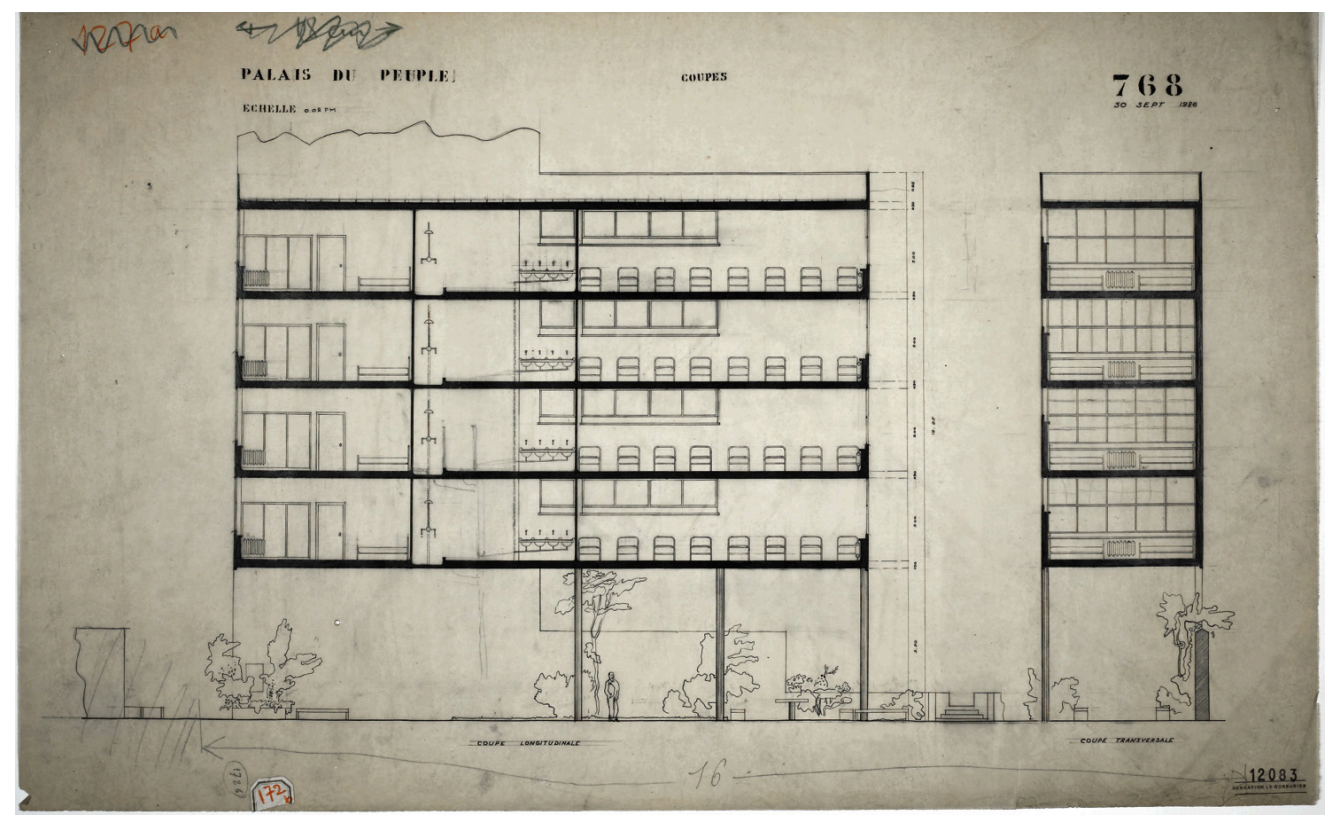

Figura 7. FLC 12083. "Secciones" del Palais du Peuple rotulada como 768 y fechada el 30 de septiembre CFLC-ADAGP 


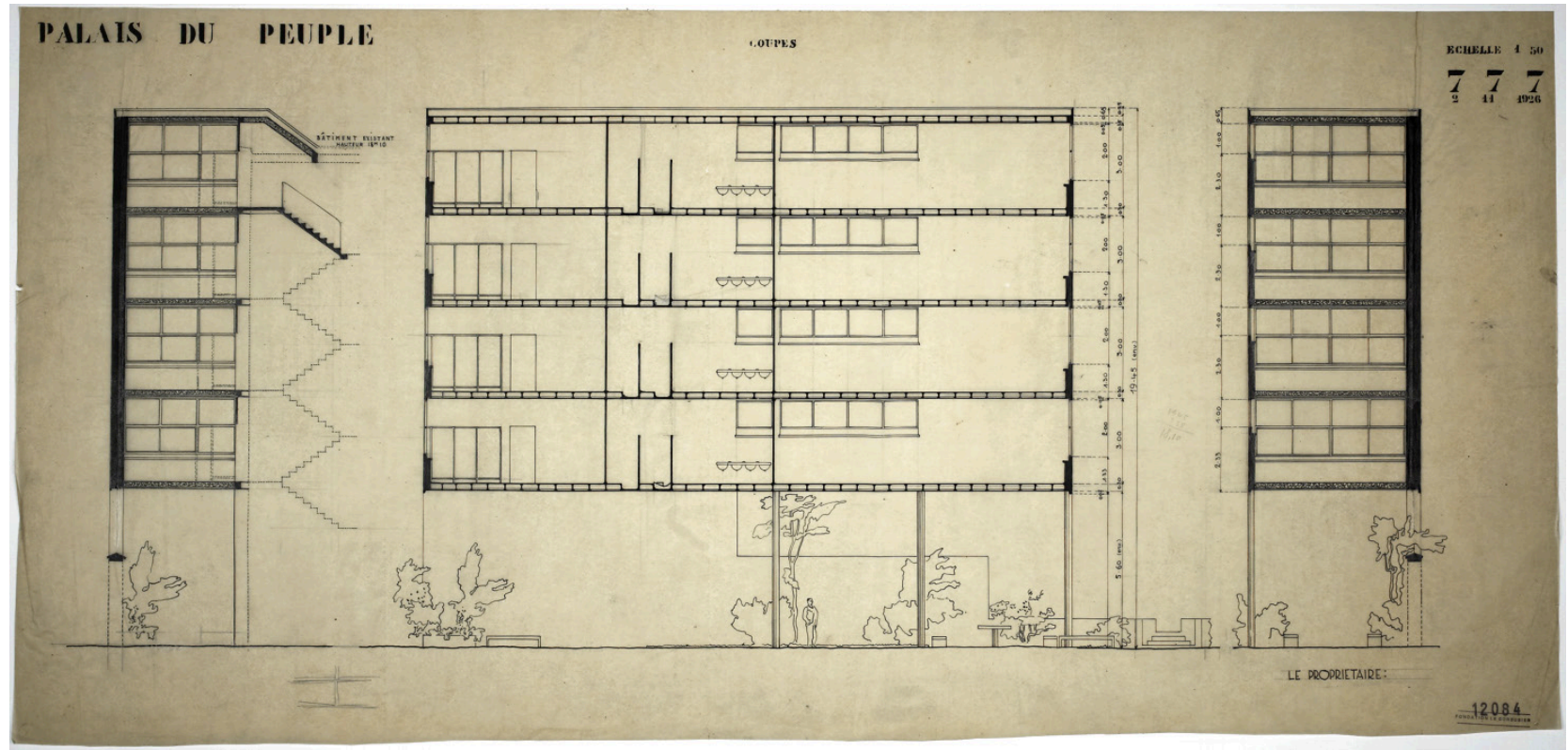

Figura 8. FLC 12084 "Secciones" del Palais du Peuple rotulada como 777 y fechada el 2 de noviembre CFLC-ADAGP to alcanzaba a imaginar desde la planta. De hecho, si las comparamos con la axonometria representada en FLC 12080 -hasta el momento, único dibujo distinto a la planta-, pronto reconoceremos las diferencias que se producen entre cada una de las versiones: desde aspectos tan básicos como el número de alturas del edificio, pues obsérvese que mientras en la axonometría se dibuja el palais como un bloque de tres plantas -más una pieza de abri (o techo) en cubierta-, en la sección se presenta con cuatro; a cuestiones más secundarias como el tratamiento del solario, en el que ya no se distinguen los ámbitos de terrasse, jardiny abri descritos en FLC 12079, sino que se dibuja como un único espacio abierto y continuo por el que todavia se puede transitar. ${ }^{21}$

Una vez queda probado que la sección es para Le Corbusier no solo un medio de representación del plan sino que es también una herramienta sobre la que se aportan algunas importantes revelaciones, no nos debe resultar extraño que si observamos ahora la sección transversal del citado FLC 12083, advirtamos también algunas de las claves que desde la planta, si bien quedaban intuidas, no terminaban de certificarse por completo. Concretamente nos referimos al modo con el que se representa el arbusto de la medianera, pues en vez de dibujarse este como un elemento esencialmente vertical que no sobresaliera de los limites del solar, el arquitecto, de manera deliberada, lo rebosa por encima del muro hasta introducir su copa en la parcela adyacente. ¿Es esta una forma de manifestar el más que probable interés de Le Corbusier porque su palais captara la luz de este espacio inmediato? ¿Valdría la pena arriesgarse a que una futura construcción vecina terminara por cegar algunos de los resquicios abiertos por el palais en la medianera?

Cinco semanas más tarde, esto es, el martes 2 de noviembre, el atelier de la Rue de Sèvres retoma el proyecto del palais con FLC 12084. Un plano que además de reeditar las antiguas dos secciones del edificio, añade una nueva vista transversal por otro de los puntos esenciales del proyecto: el enlace entre la antigua escalera y el nuevo palais; con esto, solo restaría ya una única vista longitudinal hacia la medianera para tener una visión panorámica del edificio. Pero, cpara qué representar el gran muro medianero en alzado y no en sección, pues solo así es como el arquitecto tendría la capacidad de modificar su propia estructura interna, y, por tanto, su peso sobre el plan? En este sentido, llama poderosamente la atención el extraordinario grosor que este logra adquirir aquí, pues pasa de los 25 a los $50 \mathrm{~cm}$, y, lo que es más importante, de ser un simple relleno de la estructura a constituirse como uno de los elementos portantes del palais; la solidez pasa aquí de ser un hecho aparente a establecerse como un suceso real (figura 8).

Pero en FLC 12084 no solo discrepa el espesor del muro con respecto a las secciones dibujadas en FLC 12083, sino que además de otros aspectos menores como pueda ser la modulación de los paños de vidrio del testero -antes divididos en diez piezas, ahora en ocho-, resulta llamativo el modo en que la terraza ha ido perdiendo peso conforme se sucedian cada una de las etapas. Pues partiendo de una versión (la de FLC 12080) en la que se dedicaba de manera integra una 
de las plantas al espacio de terrasse, jardin y $a b r i$, de manera paulatina, la sugerencia fue perdiendo fuerza hasta el punto de mostrarse como una simple techumbre sin posibilidad ya de poderse circular. Y es que Le Corbusier, posiblemente instigado por Madame Singer, para quien el proyecto debía alojar el mayor número de camas posible, se viera obligado a abandonar alguno de sus principios arquitectónicos.

No obstante, no parece que fuera solo un aspecto funcional el único motivo de la decisión, pues da la sensación de que las libertades del arquitecto se hallaban también coartadas por una suerte de fenómeno normativo. Nos referimos, concretamente, a la restricción en altura que existe sobre el proyecto del $p a-$ lais, pues no debemos olvidar que un hecho tan exiguo como pudiera ser la reutilización de una antigua escalera como elemento principal de paso, se convertiria, dadas las circunstancias, en la verdadera pieza de medida para el nuevo edificio. Únicamente restaba prolongarle un tramo -el que se remarca sobre la primera sección de FLC 12084- para permitir el acceso a la última de las plantas de dortoir y culminar así los «19,50 (m) de altura». ${ }^{22}$ A la postre, limite del volumen edificable.

A la par que las secciones de FLC 12084, los arquitectos del atelier desarrollaron también la planta de FLC 12085: un plano donde Le Corbusier muestra el conjunto del edificio como una secuencia abierta de piezas, ya sean interiores o exteriores, sobre las que se elude cualquier rastro de la distribución.
De hecho, de no ser por la fecha y el resto de dibujos, diriamos que más bien se trata de un plano inicial donde el arquitecto apenas realiza un primer encaje en superficie. Así, no resulta extraño que el nuevo palais se presente ante nosotros como una estancia esencialmente vacía -pues de hecho, así lo está- donde lo único que se detalla es la pieza del aseo (figura 9).

Pero al margen de todo ello, parece conveniente preguntarse sobre la verdadera utilidad que este plano ofrece al proceso que venimos desarrollando; o, cuanto menos, de desvelar su cometido más exacto. Pues, ¿por qué Le Corbusier combina un plano general del edificio con otro relativo al dominio de las instalaciones? Y, en este sentido, ¿es acaso el plan una herramienta sin dimensión capaz de gobernar (a la vez) las distintas escalas de la arquitectura; de la ciudad al baño, sin alterar su aspecto, o, incluso, modificar su naturaleza? Sea lo que fuere, lo cierto es que pese a las diferentes condiciones que se requieren para unos casos y otros, parece que FLC 12085 cimenta su sentido en más bien una suerte de artificio gráfico que remarca el peso de lo proyectado sobre lo construido, es decir, la repercusión que el nuevo cuerpo de dortoir, confinado entre el extraordinario grosor del muro medianero (tectónico y pesado) y la delgadez del cerramiento de fachada (técnico y menudo), ofrece sobre el resto de piezas del palais.

Es tal el compromiso del arquitecto con estos dos últimos planos, que de no ser por una última modificación sobre uno de los tes-
Figura 9. FLC 12085. "Plano de la planta y de las canalizaciones" del Palais du Peuple rotulada como $778 \mathrm{y}$ fechada el 3 de noviembre - CFLC-ADAGP.

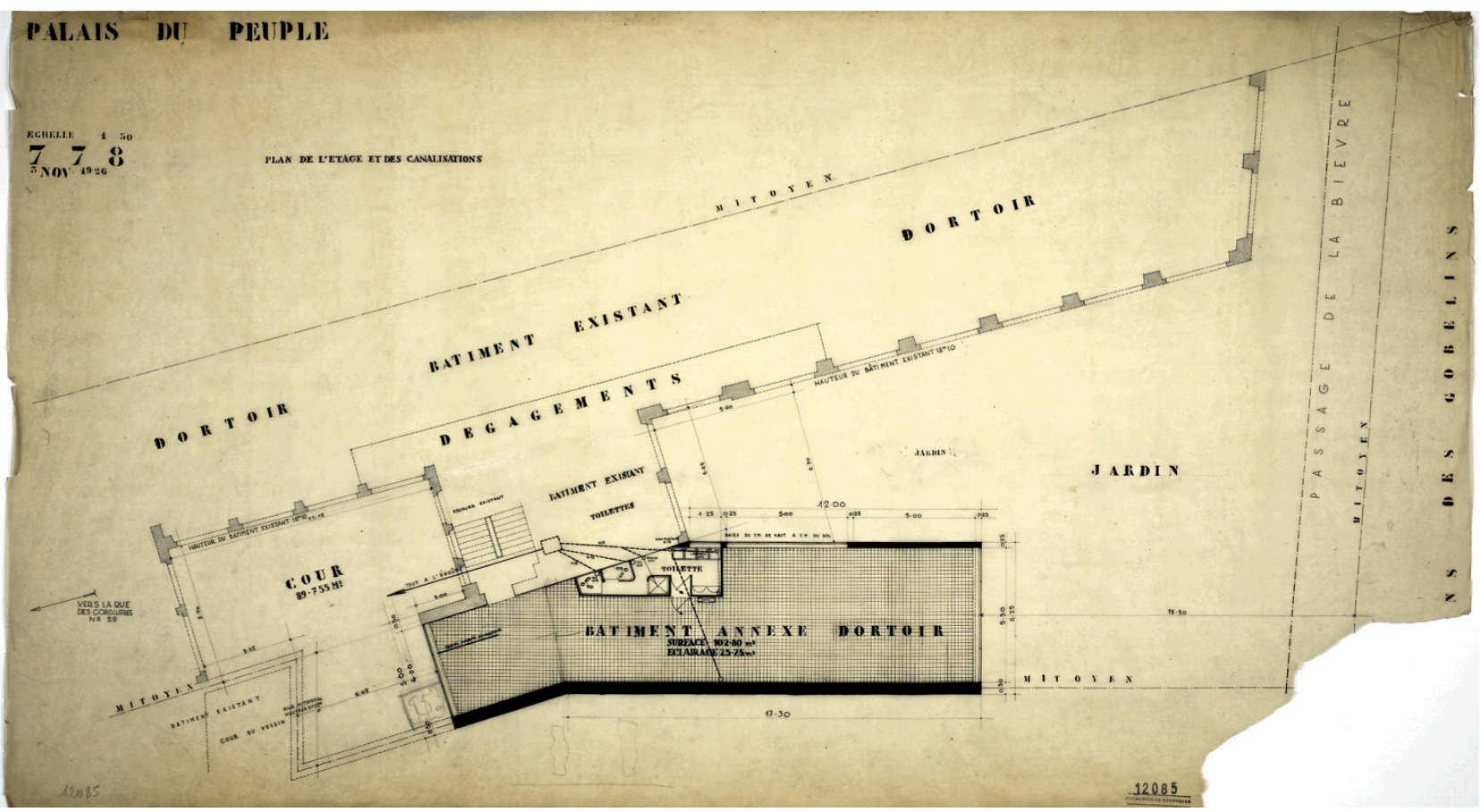


teros del bloque -concretamente, el de menor dimensión-, bien podríamos con ellos dar por concluido el proyecto. Sin embargo, diecinueve dias después de fecharse el último de estos dibujos, esto es, el lunes 22 de noviembre de 1926, los arquitectos del atelier confeccionan una nueva planta tipo (la FLC 12086) como consecuencia de un pequeño cambio producido sobre una de las dimensiones principales del palais. Se trata del testero más cercano al acceso sobre el que se apoya la cama del surveillant, pues si bien en FLC 12078, 12081 y 12085 el espacio presentaba aquí una dimensión de $4 \mathrm{~m}$, en FLC 12086 es de 4,35 m. ${ }^{23}$ En consecuencia, la fachada de $12 \mathrm{~m}$ por la que ventila el baño y sobre la que descansan los cabeceros de las ocho primeras camas -según la numeración realizada por Le Corbusier-, genera ahora una inflexión en el momento de contactar con la esquina del edificio existente; como si los 5,5 m que presenta el cuerpo principal del dortoir fueran un hecho inamovible para el arquitecto, y, por tanto, una dimensión intrínseca del plan (figura 10).

Con respecto al resto de la planta, diriamos que toda esta secuencia de sucesos se cristalizan en la única pieza construida del gran dormitorio: la sala de baños. Y es que sobre el trazado de su silueta se gestan algunos de los cambios más significativos de la planta, ya no por las continuas modificaciones que se suceden dentro de su propia distribución interna -donde distinguimos un total de cuatro versiones distintas-, sino por toda la serie de resonancias que desde aquí se desprenden sobre el resto del plan. De este modo, vemos cómo un simple cambio en la posición de los paramentos -pues obsérvese que el baño, aprovechando la inflexión que se produce entre el nuevo dortoir y el edificio existente, se acorta por uno de sus laterales- permite la incorporación de una nueva cama en la planta tipo del palais; pasando así de las veintiséis (incluyendo la del vigilante o surveillant) representadas en FLC 12078 y 12081, a las veintisiete de FLC 12086. Un hecho que Madame Singer, a buen seguro, recibiría con agrado.

Pero el proyecto del palais, pese a que sus dibujos muestran un nivel de precisión que podriamos asociar a aquellas etapas más avanzadas, todavía manifiesta ciertas dudas sobre aspectos tan esenciales como el que se representa en FLC 12093. Y es que, debido al interés que la pieza de baño ha suscitado en su artífice a lo largo de este tiempo, no debe resultar extraño que decida aislarla, ya sin nada alrededor, a la manera del que trata de resolver un difícil detalle constructivo. De este modo, queda de manifiesto la poca linealidad que para Le Corbusier tiene el proyecto de arquitectura, pues en lugar de presentarlo como un proceso reglado donde las posturas más elementales anteceden y organizan las más avanzadas, lo hace efectuando numerosos saltos, adelante y atrás, hasta encontrar la solución más adecuada en cada caso (figura 11).

Sin embargo, más que el orden preciso de cada uno de los planos del edificio, lo que realmente llama la atención aquí es la anarquía con la que estos se suceden. Pues si decíamos que durante el mes de octubre los arquitectos del atelier no realizaron ningún dibujo del palais, pues, según el "Livre noir", se hallaban inmersos en otros proyectos
Figura 10. FLC 12086. Planta tipo del Palais du Peuple rotulada como 788 y registrada en el "Livre noir" el 22 de noviembre CFLC-ADAGP.

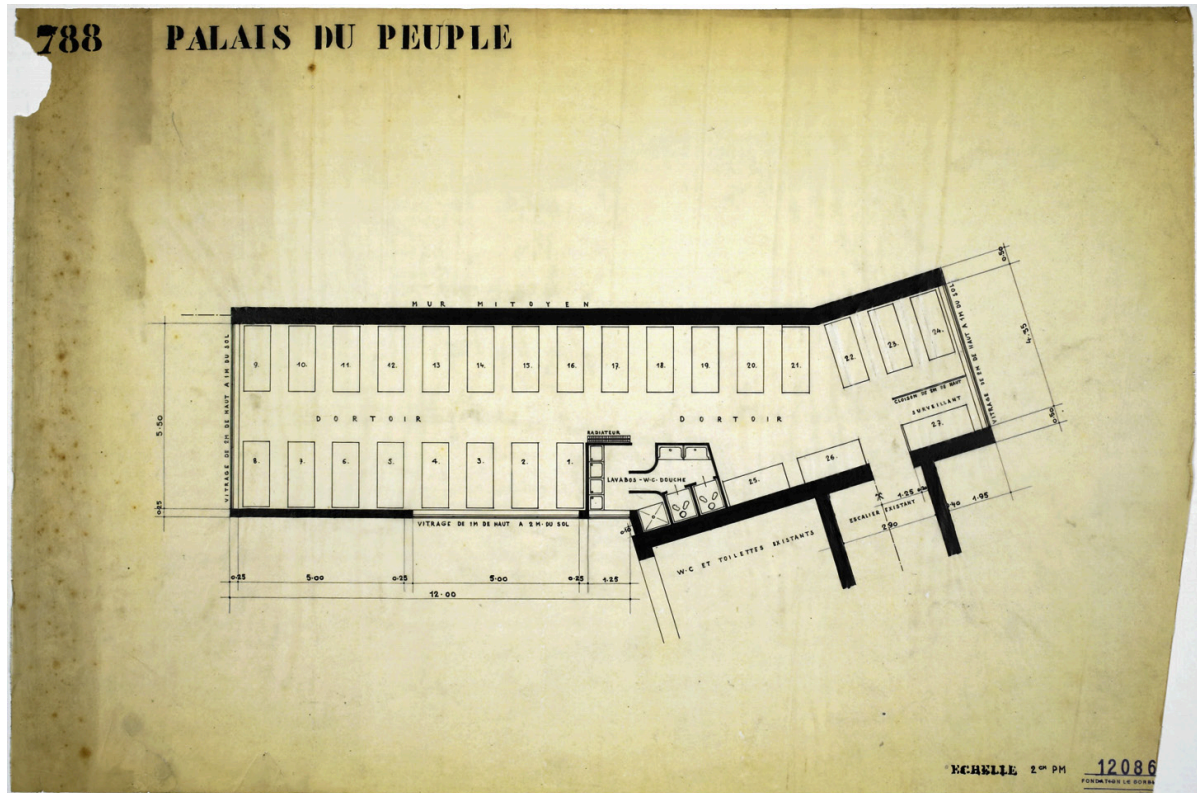




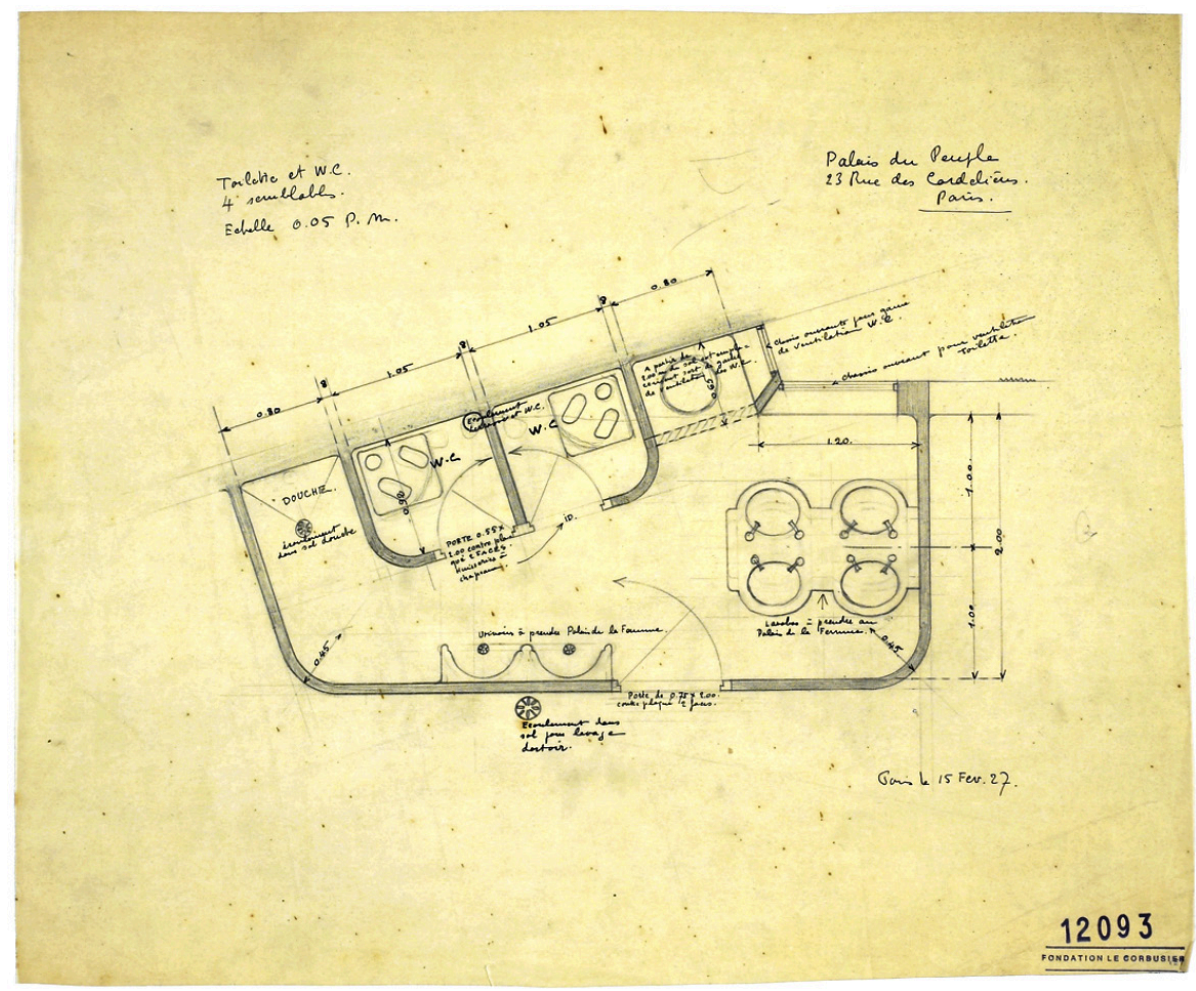

Figura 11. FLC 12093.

Detalle del cuarto de

baño del Palais $d u$

Peuple fechado el 15

de febrero de 1927 -

cFLC-ADAGP.

como las viviendas Guiette (Amberes, 1926), Cook (Boulogne-sur-Seine, 1926) y Stein-de Monzie (Garches, 1926), o, los prototipos para el barrio de Weissenhof (Stuttgart, 1927), entre otros trabajos; el plano FLC 12093 aparece ahora de manera aislada durante el mes de febrero, es decir, tres meses después de la planta tipo de FLC 12086 y uno antes del plano en rez-de-chaussée representado de manera definitiva en FLC 12087.

De este modo, llegamos así a intuir la poca repercusión que el proyecto del palais logró tener nunca sobre los tableros del atelier. Y es que si pensamos en el nutrido conjunto de trabajos que por aquel momento andaban desarrollando tanto el arquitecto como sus colaboradores, parece razonable que pudiera existir una suerte de jerarquía interna que pudiera ordenar cada una de las tareas según fuera su importancia, premura o complejidad. Sin embargo, las anotaciones caligráficas que presentan algunos de los planos ya revisados, evidencian muy a las claras la intensa participación que Le Corbusier tuvo en todas y cada una de las fases del proyecto; ya sin tener en cuenta otros bocetos completamente dibujados por él, como el que se recrea en FLC 12095 (figura 12).

¿Podriamos entonces decir, vistas las resonancias que de él se desprenden a lo largo del proceso, que se trata de un proyecto puramente corbusieriano? Si nos atenemos al cumplimiento de los cinco puntos que el arquitecto proponía como condición sine qua non de la nueva arquitectura, estariamos obligados a responder negativamente. Pues tal y como comprobamos en lo anterior el proyecto del palais, a pesar de los intentos iniciales del arquitecto, terminó por verse privado de uno de ellos: la terrasse-jardin-o, como la denominan Le Corbusier y Pierre Jeanneret en la OEuvre complète, le toit-jardin (el techo-jardin)- (Boesiger 1929, 128).

A partir de ahí, dado que se trata del único espacio exterior del palais, no nos debe resultar extraño que el interés del arquitecto recayera entonces sobre el citado jardin de los Gobelins. Por ello, es posible que a pesar de no ser otra cosa que un pequeño reducto dejado atrás por los gruesos muros del viejo bâtiment, terminara por constituirse como uno de los elementos esenciales del edificio. Tanto es así, que de los veinte planos que la "Fondation Le Corbusier" atribuye a este proyecto concreto, en cuatro de ellos (FLC 12082, 12087, 12091 y 12095) se representa el jardin de manera exclusiva; tantos, como dibujos en planta existen.

En este sentido, ¿sería lícito afirmar que el arquitecto, ya privado de aquella pretérita necesidad que suponía alzar el jardín a la cima de su arquitectura, descendiera aquí las intenciones hasta consolidarse sobre la superficie misma del edificio? Así, la célebre terrasse-jardin daría paso aquí al inédito sol-jardin. 
Figura 12. FLC 12095. Boceto previo a FLC 12087 donde se representa la planta en rez-de-chaussée del Palais du Peuple(c)FLC-ADAGP.

[Original girado $180^{\circ}$ para comparación]

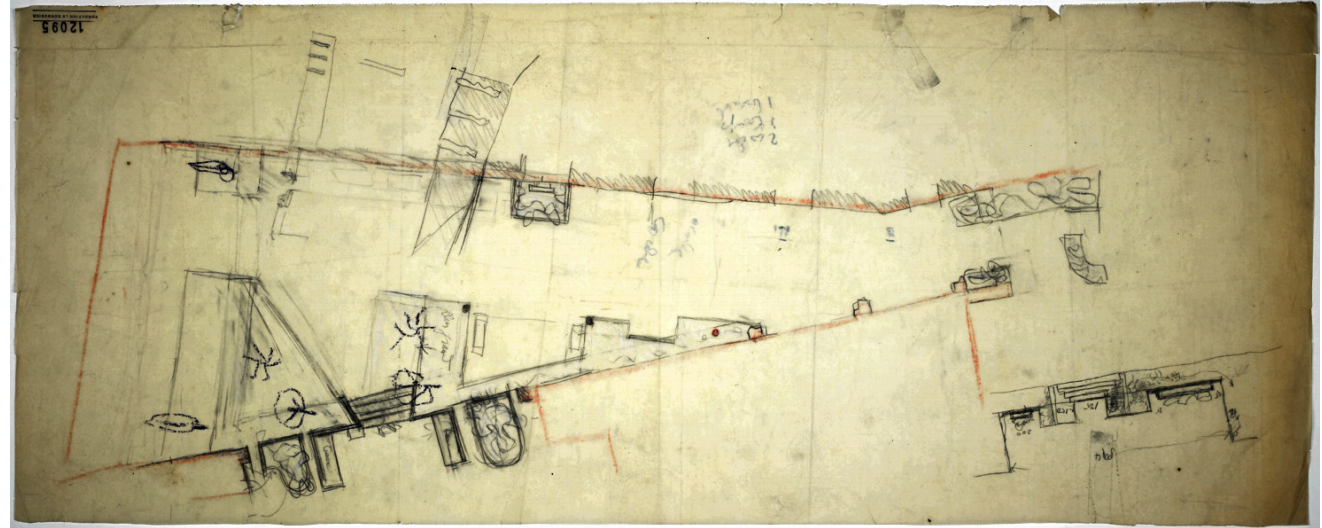

No como un fenómeno análogo, sino más bien como un medio para manifestar que pese a las evidentes diferencias entre uno y otro, lo nuevo retiene algunas características de lo viejo; como si el arquitecto, al proyectar, acudiese una y otra vez a las ideas del pasado para revestirlas de nuevos significados (Castellanos 2012, 242).

Asi, una vez llegamos a este punto, ya nada nos impide pensar que Le Corbusier, de manera cifrada, nos ofrece sobre esta planta baja -esbozada en FLC 12095, y representada de manera definitiva en FLC 12087- cada uno de los elementos típicos de sus cubiertas: desde aquel escueto espacio de abri (o techo) sustituido aquí por la huella misma del edificio; hasta las vastas áreas de gazon (o césped) que, como un recorte pretendidamente impreciso, abrazan los únicos tres pilotis del $p a-$ lais. Como si estos, además de soportar de un modo certero la pesadumbre de las cargas, debieran aparentar también un cierto aire de inocuidad sobre el plan, pues tal y como escribe el arquitecto en Précisions, "gracias a los pilotis, [...] el suelo natural permanece [y] la poesía queda intacta". ${ }^{24} \mathrm{De}$ ahí que con la misma pulcritud con que la aguja de un cirujano atraviesa la materia blanda e inconsistente de su paciente, el piloti, impasible, se hiende en la tierra de los Gobelins (figura 13).

Reconocida la obra, tan solo resta acudir a sus imágenes y comprobar así la realidad de cada una de las partes dibujadas, pues lo tácito no siempre deviene en algo explícito, y por tanto, en un gesto transmisible. De hecho, en ocasiones, la construcción no es sino una sucesión de sacrificios gracias a los cuales la arquitectura se consagra a lo superfluo y aspira a un ideal más puro, más lejano e inaccesible (Castellanos 2012, 159); como si esta, una vez liberada del lastre de lo sobrante, pudiera refrendar su permanencia, o, por contra, su apertura hacia un cambio estable y claro (figuras 14 y 15).

Pero en el palais diriamos que ocurre un hecho contrario, pues a la vista de las fotografias -ya sean estas desde los interiores o los exteriores- se comprueba que el acto de

Figura 13. FLC 12087. Planta del "jardin" del Palais du Peuple rotulada como $843 \mathrm{y}$ registrada en el "Livre noir" el 18 de marzo de 1927 - CFLC-ADAGP.

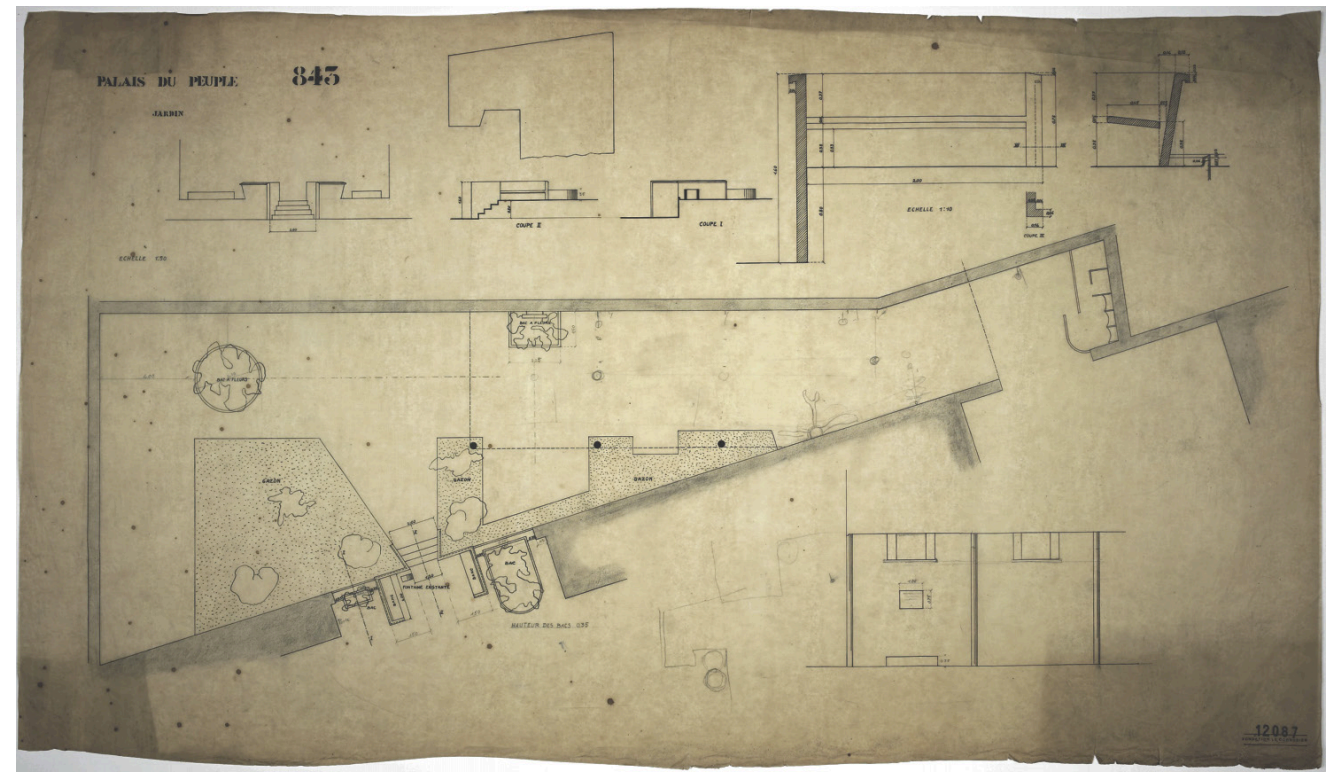


construir no es sino un episodio más del de proyectar, pues por definición, un proyecto no deja de serlo hasta el momento mismo en el que este se constituye. Así, las obras, durante su concepción material, poseen todavia la posibilidad de descubrir aspectos que habían quedado atrapados en la profundidad de los planes: bien por tratarse de ideas que dada su complejidad o su escaso nivel de concreción, se pasan por alto en los dibujos; bien, como consecuencia del artificio gráfico que supone aparentar aquello sobre lo que, de un modo u otro, el proyecto cimenta su sentido.

A partir de ahí, no es casual que el arquitecto decidiera evitar sobre la planta del palais cualquier tipo de intromisión o interferencia que pusiera en duda la integridad del que es, con toda seguridad, el elemento más llamativo del plan: el muro medianero. $\mathrm{Y}$ es que, representado este (una y otra vez) como una pieza enteramente maciza y densa, lo cierto es que sobre él la realidad se manifiesta de un modo bien distinto, esto es, como un elemento tocable sobre el que el arquitecto realiza importantes revelaciones.

Bastaba un vistazo sobre las imágenes del palais para observar que Le Corbusier aquí, en este espacio de incertidumbre, no pretende otra cosa que enfrentar la esencia de dos realidades bien distintas: el plan paralysé de la casa -o, del palacio- de piedra, con el plan libre del palacio -o, de la casa- moderna. Uno frente a otro, como si el bloque del palais no fuera sino una suerte de espacio intermedio entre elementos que tratan de asentar su permanencia: desde el muro medianero y el piloti de la planta baja, a la ventana cuadrada (abocinada) y el pan de verre de las plantas tipo. Una unión inesperada fruto de la imposible vecindad entre discrepancias que, en ocasiones, logran compartir un mismo punto de acuerdo.

\section{Conclusión}

Este Apunte sobre el palais materializa un tiempo. El tiempo de un proyecto casi desconocido llevado a cabo entre los muros de aquel discreto patio de la Rue des Condelières de París.

El escrito, a la manera de un diario, trata de dar orden a los siempre embarullados, arrítmicos y zigzagueantes procesos de Le Corbusier, "llenos de arrepentimientos y de seguridades, de errores y de certezas, de saltos atrás y de fulminantes previsiones" (Quetglas 2009, 19). La tarea era la de, a través de los trazos todavía legibles sobre los planos del proyecto, posicionarnos en la mente del
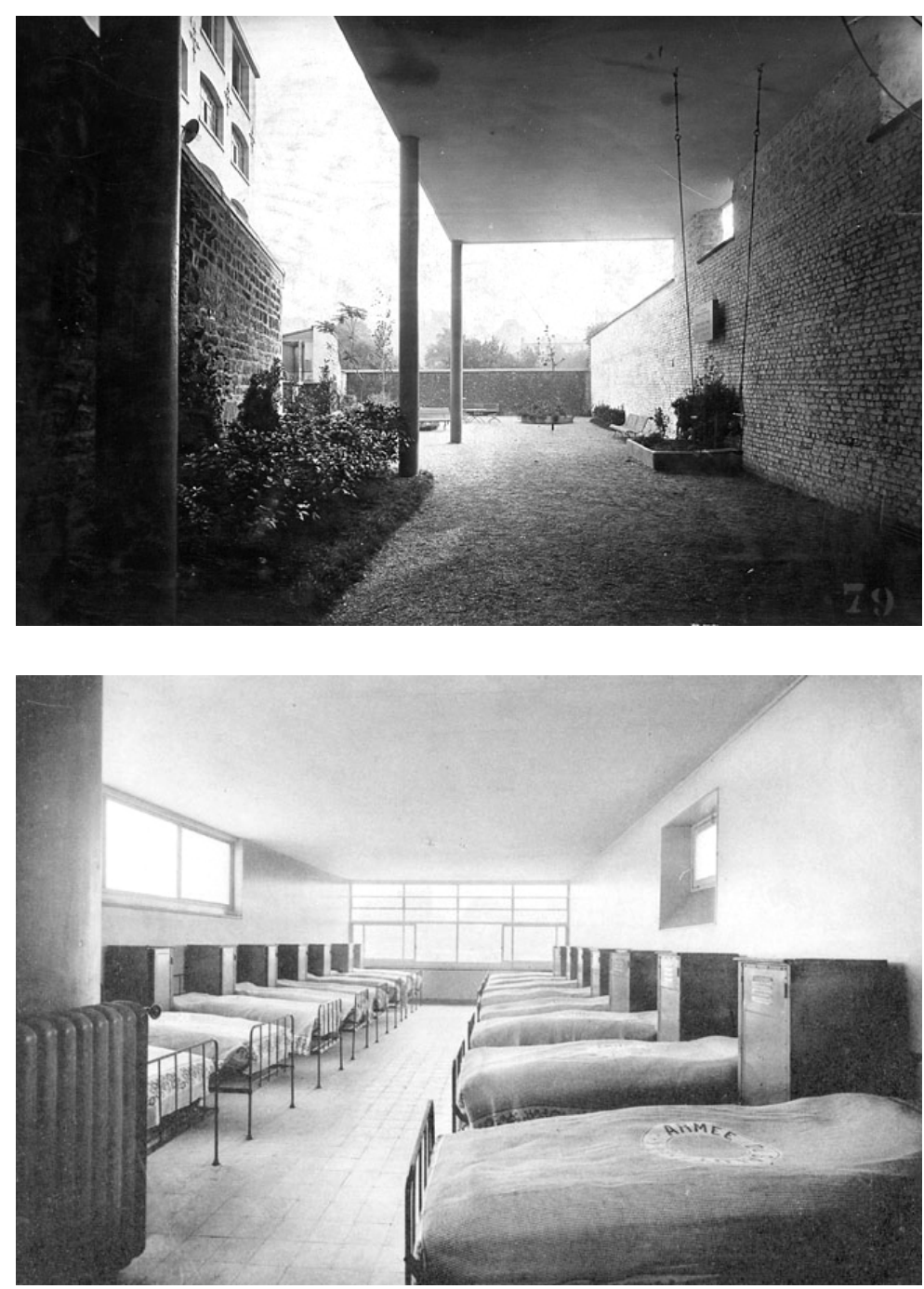

maestro y extraer de ahí algunas de las pasiones, delirios u obsesiones que debieron formar parte, aunque solo fuera por un instante, del imaginario más íntimo del arquitecto.

Fundamental será para este escrito la relación tan estrecha que para Le Corbusier existía entre el gran palais y la pequeña maison, y que, entre otros logros, le había llevado en 1928 a escribir Une maison - Un palais. À la recherche d'une unité architecturale. Sin duda, un libro importante en el que por fin entendimos, si es que todavía quedaba alguna duda, que su arquitectura no era más que una disciplina indeterminada, absoluta, potencialmente infinita, sin escala ni dimensión, capaz de contener con un único e inabarcable gesto el conjunto de necesidades del hombre.

Puesto no creo llegar a poder, les cedo a los mismos lectores el privilegio de evaluar la importancia de esta escueta investigación. Suya será la responsabilidad de comprender y compartir algunas de las ideas que de aquí se desprenden, de decir o desdecir sus afir-
Figuras 14 y 15. Jardin en planta baja e interior de una de las plantas tipo del Palais du Peuple CFLC-ADAGP. 
maciones; de aportar, en definitiva, sus propios fragmentos de memoria a esta suerte de escrito, todavía imperfecto, en pleno proceso de desarrollo.

Quedará por referir, si acaso, un último apunte sobre el más que llamativo estado en el que se halla la cuestión del Palais $\mathrm{du} \mathrm{Peu-}$ ple. Y es que si bien han sido numerosos los estudios que de un modo $u$ otro se han referido a la arquitectura de este edificio, ninguno de ellos profundizará como aquí sobre algunas de las cuestiones más ocultas del proceso de proyecto. De ahí, quizás, lo adecuado de este escrito: tan arriesgado por un lado, como ineludible y necesario por el otro.

\section{Notas}

1 Palais du Peuple de París (1926), Palais de la Société des Nations de Ginebra (1927), Palais du Centrosoyus de Moscú (1928), Palais des Soviets de Moscú (1930), Palais des Nations Unies de Nueva York (1947), Palais des Filateurs de Ahmehabad (1951), Palais du Gouverneur de Chandigarh (1951), Palais de l'Assemblee de Chandigarh (1951) y Palais des Congrès de Estrasburgo (1962).

2 Traducción al castellano del autor: "Destiné à remplir des fonctions précises à l'usage d'hommes "tout-venant»". En (Le Corbusier 1958, XI).

3 Traducción al castellano del autor: "Et par palais nous voulions signifier que chaque organe de la maison, par la qualité de sa disposition dans l'ensemble, pouvait entrer en tels rapports émouvants dévoilant la grandeur et la noblesse d'une intention. Et cette intention, c'était, pour nous, larchitecture. / [...] Est-ce autre chose "que étudier la maison pour homme courant", "tout venant", est-ce autre chose que retrouver les bases humaines, l'échelle humaine, le besoin-type, la fonction-type, est-ce autre chose que retrouver l'émotion-type?".

4 Conferencia titulada "Una casa - Un palacio. El Palacio de la Sociedad de Naciones de Ginebra", como referencia a su libro Une maison - Un palais. À la recherche d'une unité architecturale. Hemos de tener presente que tal y como demuestra Tim Benton en su libro The rhetoric of modernism: Le Corbusier as a lecturer, algunas conferencias presentaban un orden distinto en las cuatro fuentes de las que se tiene constancia: un primer listado de lecturas para Buenos Aires fechado el 28 de julio de 1929 (FLC C3 (7) 108), una suerte de reorganización que el autor ubica sobre el 11 de octubre (GRI 920083-01 (2) 3), el orden que Le Corbusier les daría en Précisions y la secuencia cronológica real. Tal es el caso de esta séptima conferencia, que aparece en octavo lugar en el resto de documentos. Véase (Benton 2009, 136).

5 Traducción al castellano del autor: "Lorsque nous avions terminé notre projet, de constater que nous avions exactement parcouru les mêmes chemins qu'à concevoir une usine, un plan de ville, une maison, un mobilier".
6 Traducción al castellano del autor: "Le palais, lui, sera une maison". En (Le Corbusier 1928, 84).

7 Traducción al castellano del autor: "Notre joie a été de traiter notre Palais des Nations comme nous avons traité nos maisons. / [...] Cette clarté et cette pureté, n'est-ce pas le signe des temps modernes? Et n'est-ce pas aussi comme le signe même de la nouvelle institution qui, à Genève, devrait répondre à l'espoir des sociétés nouvelles?".

8 "Ejército de salvación". Movimiento internacional instaurado en Francia en 1881 de la mano de Catherine, hija del verdadero fundador, el General inglés William Booth. Además del proyecto al que se hace referencia en el escrito, el atelier de Le Corbusier proyecta otros dos edificios para 1'Armée du Salut: la Cité de Refuge (París, 1929) y el Asile flottant (París, 1929).

9 Traducción al castellano del autor: "Luusage d'hommes "tout-venant". En (Le Corbusier 1958, XI)

10 De nombre, Winnaretta Singer. Heredera de la empresa de máquinas de coser Singer Corporation. Véase (Fondation 2010, 1). A propósito de la introducción de Ivan Zaknic sobre el Palais du Peuple (1926).

11 Traducción al castellano del autor: "En recouvrant ce terrain négligé, on laissait libre au-devant des nouveaux dortoirs et au-devant des anciens dortoirs du Palais du Peuple, un jardin en plein soleil et le vaste dégagement des domaines des Gobelins. La solution primitivement envisagée par d'autres architectes, consistait à couvrir ce jardin ensoleillé par des dortoirs dont la mitoyenne eut été orientée au sud et les fenêtres au nord; le bâtiment lui-même, ainsi placé eût projeté son ombre sur les constructions déjà existentes".

12 Según los "LC Plans", la cantidad de planos asociados a cada uno de los proyectos es la siguiente: Palais du Peuple de París (20 planos), Palais de la Société de Nations de Ginebra (277 planos), Palais du Centrosoyus de Moscú (870 planos), Palais des Soviets de Moscú (717 planos), Palais des Nations Unies de Nueva York (177 planos), Palais des Filateurs de Ahmehabad (171 planos), Palais du Gouverneur de Chandigarh (856 planos), Palais de 1'Assemblee de Chandigarh (805 planos) y Palais des Congrès de Estrasburgo (253 planos).

13 Apuntar que existe un pequeño desfase entre la rotulación de FLC 12078 (751), FLC 12079 (752) y FLC 12080 (753) y el número con el que estos aparecen inventariados en la página 16.2 del "Livre noir" -o, FLC S1-16-1-012-, que el atelier del 35 de la Rue de Sèvres tenía como "libro de registro" de planos, donde aparecen como 750 , 751 y 752 , respectivamente.

14 Obsérvese que en el margen superior de la lámina el arquitecto anota "4 étages" (4 plantas), muy posiblemente para referirse al número de veces que se repite esta "étage courant" (planta tipo) del palais.

15 "Muro medianero" y "muro existente". Sobre el dibujo, diferenciados con un sombreado en negro y otro en rojo, respectivamente. 
16 "Planta paralizada" y "planta libre". Conceptos que, en 1929, utilizará Le Corbusier a propósito de las conferencias en Buenos Aires a "Los amigos de las artes", para comparar la "planta paralizada" de la casa de piedra con la "planta libre" de la casa de acero y hormigón. Véase (Le Corbusier 1960, 123-125).

17 De entre todas ellas, cabe resaltar la semejanza que se produce entre este espacio de abri y el de Caveidium -del latín, Cavaedium (atrio típico de las viviendas romanas)- de la Casa del Nogal que Le Corbusier visitara durante sus viajes por Oriente (1911), y que definiria como "quatre colonnes au milieu (quatre cylindres) élèvent d'un jet vers l'ombre de la toiture (Trad. del autor: cuatro columnas en el centro (cuatro cilindros) que se elevan directamente hacia la sombra de techo". Véase (Le Corbusier 1958, 148).

18 "L’architecture c'est de la circulation". Véase Torres, Jorge: "La arquitectura es la circulación". En (Torres 2012, 213). Título con el que el autor trata de confrontar la diferencia de significado existente entre la versión francesa -y, por tanto, original de la frase- (en Précisions. Paris: Éditions Vincent, Fréal et Cie, 1960. p. 48), y la malograda traducción al castellano (en Precisiones. Barcelona: Poseidón, 1999. p. 64).

19 Traducción al castellano del autor: "La conséquence du calcul et l'aboutissement élégant de la tendance moderne à l'économie". En (Le Corbusier 1960, 51).

20 "Secciones". Término con el que Le Corbusier rotula a FLC 12083.

21 A pesar de que en la sección longitudinal representada en FLC 12083 se obvia la puerta de salida a la terraza -en teoría, ubicada en la misma posición que en el resto de plantas-, en vistas del antepecho con el que se remata el volumen del palais, diriamos que Le Corbusier todavía mantiene intacta aquí esa antigua idea, casi obligada, de circular por la cubierta.

22 "19,5 de haut". Véase FLC 12080. Anotación caligráfica (a lapicero) realizada por Le Corbusier como referencia a la altura máxima que debía alcanzar este nuevo bloque del palais. De hecho, obsérvese que en FLC 12084 la altura total del edificio es de $19,45 \mathrm{~m} ; 50 \mathrm{~cm}$ menor que en FLC 12083, donde la altura total era de 19,95 $\mathrm{m}$.

23 Téngase en cuenta que en la primera toma de datos que el arquitecto plasma sobre FLC 12097 la cota en este punto es de 4,37 m, mientras que en FLC 12089 (copia heliográfica) lo es de 4,35 $\mathrm{m}$-al igual que en la planta definitiva del palais, o, FLC 12086-. Con esto, cabe decir que en FLC 12078, 12081 y 12085, donde el testero quedaba reducido a $4 \mathrm{~m}$, los arquitectos del atelier incurrieron en un error que no se subsanaria hasta el citado FLC 12086; ochenta y un dias después de realizarse el primero de los dibujos del palais: el FLC 12078.

24 Traducción al castellano del autor: "Grâce aux pilotis, [...] le sol naturel demeure, la poésie est intacte”. En (Le Corbusier 1960, 50).

\section{Bibliografia}

Benton, Tim. 2009. The rhetoric of modernism: Le Corbusier as a lecturer. Basel, Boston, Berlín: Birkhäuser Verlag AG.

Boesiger, Willy (edit.). 1929. CEuvre complète 19101929. Zúrich: Girsberger.

Castellanos, Raúl. 2012. Plan Poché. Barcelona: Arquia/Tesis $n^{\circ} 36$.

Fondation Le Corbusier. 2010. Le Corbusier. DVD Plans $n^{\circ}$ 2. París: Fondation Le Corbusier.

Le Corbusier. 1928. Une maison - Un palais. À la recherche d'une unité architecturale. Paris: Les Éditions G. Crès et Cie.

Le Corbusier. 1958. Vers une architecture. París: Éditions Vincent, Fréal et Cie.

LE Corbusier. 1960. Précisions sur un état présent de l'architecture et de l'urbanisme. Paris: Éditions Vincent, Fréal et Cie.

QueTGLas, Josep. 2009. Les Heures Claires: proyecto y arquitectura en la villa Savoye de Le Corbusier y Pierre Jeanneret. Barcelona: Massilia.

ToRres, Jorge (coord.). 2012. Le Corbusier. Mise au point. Valencia: General de Ediciones de Arquitectura.

\section{Créditos de las imágenes}

Los derechos de todas las imágenes son propiedad de la Fondation Le Corbusier de París.
Fecha final recepción artículos: 16/04/2018

Fecha aceptación: 22/06/2018

Artículo sometido a revisión por dos revisores independientes por el método doble ciego. 